\title{
Research collaboration best defense against Pierce's disease
}

W.R. GOMES

Vice President

Agriculture and Natural Resources
$\mathrm{T}$ The threat of Pierce's disease to wine grapes has been the subject of headlines for the past 2 years. The truth is that the Xylella fastidiosa bacterium that causes the disease may also pose a threat to California's raisin and table grapes, almonds and alfalfa. Related strains harm oleander here, and in other parts of the world damage citrus, coffee, plums and peaches.

Although Pierce's disease has been found in California grapes since at least the 1880s, the invasion of the glassywinged sharpshooter (GWSS) has accelerated the spread of $X$. fastidiosa in vineyards. A vine infected with $X$. fastidiosa typically dies within a year or two; currently there is no known cure.

According to estimates by California Department of Food and Agriculture (CDFA) and local growers, since 1997 Temecula Valley (Riverside County) has lost between 500 and 800 acres of wine grapes. Because GWSS thrive on several species of common plants, they have spread rapidly throughout Southern California. Infestations in southern San Joaquin Valley and isolated finds in Sacramento Valley can be attributed to trade, including the movement of ornamental plants.

The combination of GWSS and X. fastidiosa presents a complex problem, best addressed by collaboration and coordination among public institutions and agencies and private industry. Because the threat is so far-reaching, we can't afford to try one approach at a time. We need a comprehensive strategy with teams of people working concurrently on near- and long-term solutions.

Perhaps the best long-term solution is to breed plants resistant to Pierce's disease, but that will take years. In the meantime, GWSS must be controlled because just a few of the voracious insects can infect an entire vineyard. GWSS is endemic to the southeastern United States, and as a result the most valuable grape varieties cannot be commercially grown there.

UC scientists and their colleagues are attacking Pierce's disease through a variety of disciplines, including plant pathology, disease epidemiology, insect behavior and plant breeding (see p. 8). UC studies have shown that soil applications of the insecticide imidacloprid appear to inhibit the acquisition and transmission of the bacterium. Under ideal field conditions, the insecticide kills $90 \%$ to $95 \%$ of GWSS, which still isn't high enough for disease management. However, sharpshooters that survived the chemical treatment and fed on Pierce's disease-infected plants were much less likely to transmit the bacterium to healthy plants.

Native parasitic wasps also seem to lower GWSS populations, and introduced wasps in the same family may be an effective complement. Data on last year's releases are not yet available. However, an effective biocontrol would go a long way toward helping the nursery industry meet quarantine regulations. Meanwhile, California nursery growers are working with CDFA to develop a shipping protocol to prevent the spread of GWSS.

UC scientists and colleagues have found that proximity of citrus could influence the incidence and severity of Pierce's disease in grapes (see p. 13). They have also learned details of GWSS biology that may help predict egglaying behavior (see p. 19) and have identified insecticides to suppress the sharpshooter in vineyards (see p. 22).

UC Cooperative Extension has disseminated important information to growers, and UC farm advisors are working closely with growers and officials statewide to monitor sharpshooters and Pierce's disease. They are also teaching growers the disease epidemiology and strategies to reduce its incidence. In the North Coast, where the bluegreen sharpshooter spreads $X$. fastidiosa from infected riparian plants to grapevines, advisors are working with local authorities and holding vegetation management workshops to reduce blue-green sharpshooter populations and enhance riparian habitat.

About $\$ 10$ million has been allocated for research to halt the spread of Pierce's disease in California, and additional funding is being requested. The proposed 2001-2002 state budget would allocate $\$ 8.9$ million to CDFA for control, containment and research. A bill by Assemblymember Patricia Wiggins (D-Santa Rosa) would raise another \$5 million annually in matching research funds from the wine grape community; the initial assessment for the 2001-2002 harvest season would be $\$ 3$ per thousand dollars gross value of grapes. At the federal level, the House appropriations bill for agriculture currently proposes $\$ 3$ million for the U.S. Department of Agriculture (USDA) Agricultural Research Service Center at Parlier, $\$ 10$ million for the USDA Animal and Plant Health Inspection Service, and \$2 million for a special research grant to UC.

With continuing cooperation among CDFA, USDA and UC scientists, and coordination with the private sector, we are staving off the Pierce's disease threat and moving toward solutions. 